Gazi University
Journal of Science
http://dergipark.gov.tr/gujs

\title{
Assessment of Carbon Footprint of a Campus with Sustainability Initiatives
}

\author{
Emre ARTUN* (D) \\ Middle East Technical University, Northern Cyprus Campus, Petroleum and Natural Gas Engineering Program, Mersin 10, 99738, TURKEY
}

\begin{abstract}
Highlights
- Carbon footprint of Middle East Technical University - Northern Cyprus Campus is estimated.

- A spreadsheet-based tool is developed that includes a probabilistic assessment section.

- Positive contributions of sustainability initiatives in the campus are demonstrated.

\section{Article Info}

Received: 24 Apr 2020

Accepted: 01 Jan 2021

\section{Keywords}

Carbon footprint

Carbon emissions

Sustainability

Abstract

Carbon footprint of a 10-year old university campus is estimated using IPCC Tier 1 Methodology. Key sources and sinks that cause carbon emissions were identified. Electricity, fuel, food and paper consumption were considered as the key items that would increase the emissions. Trees and recycling practices were considered as the key items that would reduce the emissions. Through communication with campus staff and data collection, annual consumption/production data were compiled in a spreadsheet application that uses these data to estimate the amount of carbon that is emitted per year. It was demonstrated that there has been a reduction in the carbon emissions between 2011 and 2017 due to the sustainability initiatives that were launched during that time in the campus. To analyze future years and address the uncertainty in the data, the spreadsheet allows to perform a probabilistic estimation through Monte Carlo simulation and analysis.
\end{abstract}

\section{INTRODUCTION}

Due to the activities of human beings, the balance of the mother nature has been affected significantly especially after the developments that happened after the Industrial Revolution. The magnitude of these effects is most commonly known and quantified as climate change, which includes the changes within the climate such as the average rainfall, air/sea temperatures, etc. It has been widely accepted that the increase in the concentration of greenhouse gases has been playing a major role in these changes. Carbon-dioxide is considered to be the most critical greenhouse gas that has the highest impact on the climate. Even in the case of the most desirable yet unrealistic scenario of preventing carbon-dioxide emission altogether starting today, it would take around 1000 years to reverse its effects on the climate [1]. It has been proven that mainly human activities cause these emissions. The first step of improvement is to scientifically measure necessary parameters and understand the current condition [2]. Only then, necessary actions can be planned for and taken. Carbon-footprint concept has been introduced as a means of a method to estimate the quantity of carbon-dioxide emitted [2]. While there are varying definitions in the literature, carbon-footprint stems from the broader concept of ecological footprint $[3,4]$. Carbon footprint is defined as a quantitative measure of the cumulative amount of emitted carbon-dioxide in mass units that is caused by a certain population, a certain system or an undergoing activity directly or indirectly [5]. In this definition, all sources, sinks and storage aspects must be taken into account within the boundaries of the population, system or activity under consideration [6]. To reduce the uncertainties and number of assumptions needed in the estimation, the calculation is not carried out in area units [7].

While carbon footprint can be calculated for any particular area or population, it is also common to calculate carbon footprint for university campuses. Many universities have initiated sustainability programs with the main goal of establishing sustainability and environmental friendliness and awareness. Carbon footprint estimations together with other activities through these initiatives have been very common. There are a number of examples in the literature, in which different universities have calculated their carbon emissions 
or had an attempt to quantify the university's contribution to climate change [8-11]. In a recent study, carbon footprint was calculated for Middle East Technical University (METU) - Ankara Campus [2], which was part of the motivation for proposing a similar study for METU Northern Cyprus Campus (METU NCC) since the Ankara Campus is the main of campus of the University. Carbon-emission sources of both campuses are slightly different, but a similar methodology was envisioned to be applicable to METU NCC, which is based on the IPCC Guidelines for National Greenhouse Gas Inventories (Life Cycle Assessment) Tier 1 [12-14]. This methodology is based on the consumed amounts of the emission sources and their corresponding emission factors.

METU NCC was established in 2005, as the first overseas campus of a Turkish university, by the foundation law adapted in 2003 and agreement between the governments of Republic of Turkey and Turkish Republic of Northern Cyprus [15]. It is one of the 20 universities currently registered by the Higher Education Planning, Evaluation, Accreditation and Coordination Council of Turkish Republic of Northern Cyprus [16]. Among these 20 universities, 7 of them provide education in a campus environment. Number of staff members to students ratio at METU NCC averaged at 9.6 between 2010-2017, which places the campus at a reasonable rank when compared with top 100 universities in the world in terms of this ratio [17]. Similar to many other universities, a sustainability initiative, Green Campus Initiative, has been established in the Northern Cyprus Campus and several actions have been implemented throughout the time period of its presence to make the campus a greener one. Some examples include:

- Planting trees,

- Shuttle buses for the commute of campus staff/students,

- Promoting bicycles as a means of transportation (e.g., bicycle rental, road signs to share the road among pedestarians bicycles and automobiles),

- Solid waste reduction and recycling of thrash,

- Flea markets to promote buying used goods,

- Making use of trash material through art activities,

- Water and electricity use efficiency practices.

As indicated in the METU NCC Green Campus Strategic Plan, reducing carbon dioxide emissions per capita and indoor unit area by more than $10 \%$ by year 2017 is one of the strategic goals of this initiative [18]. However, currently there has not been any measured data or indicator, that can be directly used to assess if this strategic goal has been achieved through these activities. Being a new and modern campus, data collection activates have been significant as compared to older universities where such practices may not be a part of the university-culture. On the other hand, in order to maintain a sustainable environment in the campus, it is very important to have a certain methodology to continuously analyze the past situation, assess the current situation, and forecast the future situation regarding the carbon emissions. Therefore, in this study, we wanted to establish a standard workflow and user-friendly tool in the form of a spreadsheet application for carbon emission calculations. Our primary goal was to use this tool to have an estimation of the carbon footprint of the Middle East Technical University - Northern Cyprus Campus as much as the data permits. The outcome includes a spreadsheet-tool which can be easily updated with new data that can be used to analyze historical data and forecast future carbon footprint. This would provide guidance to take appropriate and possible actions to reduce the carbon-dioxide emissions. To summarize, the objectives of this study are the following:

1. To develop a spreadsheet-based tool, to estimate the carbon footprint of METU NCC at any given time,

2. To calculate the carbon footprint (historical, current and future) as much as the collected data permit,

3. To compare the calculated change in carbon footprint with time, with the strategic goals of METU

NCC Green Campus Initiative. 


\section{MATERIAL AND METHODS}

In this section, the methodology followed to achieve the goals of this study is presented. First, the way the spreadsheet tool is designed and constructed is explained. Then, data collection procedures are summarized together with the key data used in the assessment.

It is aimed to design and develop a spreadsheet that is both easy to maintain and understand, and at the same time comprehensive to include all different types of data that are available. Based on the collected data, 5 main categories are identified to be used for carbon emission calculation:

\section{Electricity \\ 2. Fuel \\ 3. Food \\ 4. Paper \\ 5. Sink.}

For the carbon footprint estimation, two worksheets are developed for deterministic and probabilistic analysis. In addition to the five input and intermediate calculation sheets for each category above, a supplementary data sheet is also added to input data such as number of students, number of employees, food consumption and commute habits of people associated with the campus as a function of time. Intergovernmental Panel on Climate Change (IPCC) Tier-1 Methodology is used, which is the most basic applicable methodology to calculate carbon footprint. Tier 1 approach uses a default emission factor at calculation, in which several factors do not depend on location of the activity [13]. This approach requires calculation of the emission through emission factors. After identifying the sources/sinks for carbon emission, two key pieces of data needed are:

- Annual consumption data for the specified source/sink,

- Emission factor for the specified source/sink (i.e., $\mathrm{kg} \mathrm{CO}_{2} /$ unit consumption)

Multiplying these two numbers would result in the mass of $\mathrm{CO}_{2}$ emitted for the given source, for a given year. Therefore, our data collection focused on finding or collecting necessary data that we can use for calculating annual consumption of each source. Table 1 shows the data sources used.

Second step of data collection was to collect carbon emission factors from published sources. The spreadsheet's structure is shown in Figure 1. Emission source/sink data are shown in orange-colored tabs. Blue tabs indicate sheets for analyzing the results. Each data sheet is structured as shown in Figure 1. On top of the sheet, there are emission source/sink names and their associated factors with specified units. Yearly calculations are shown under the emission name and factor as a separate table. Years between 20112025 are shown. A supplementary data sheet is included in the workbook, to include eating habits survey results, commute survey results, number of full-time and part-time academic and administrative employees and number of students as a function of year.

There are 2 sheets designed to view and analyze results: Deterministic and Probabilistic. Spreadsheet for deterministic results (Figure 2) shows yearly carbon-dioxide emissions based on the data provided, and a graphical representation is included as a pie-chart to see the contributions of different sources to the carbon emissions. Kilogram of $\mathrm{CO}_{2}$ emitted per capita is also calculated based on the number of employees and students in the campus. 
Table 1. Types and sources of data collected

\begin{tabular}{|l|l|}
\hline Type of Data & Source \\
\hline $\begin{array}{l}\text { Numbers of people studying, working in the } \\
\text { campus and flying professors }\end{array}$ & METU NCC Annual Activity Reports \\
\hline Electricity consumption / production & METU NCC Construction Services \\
\hline $\begin{array}{l}\text { Diesel fuel consumption, number of cars } \\
\text { entering to the campus, number of trees, } \\
\text { consumed paper }\end{array}$ & METU NCC Administrative Affairs \\
\hline $\begin{array}{l}\text { Food consumption, transportation of campus } \\
\text { residents }\end{array}$ & Online survey $(\sim 400$ respondents $)$ \\
\hline Emission factors & Literature \\
\hline
\end{tabular}

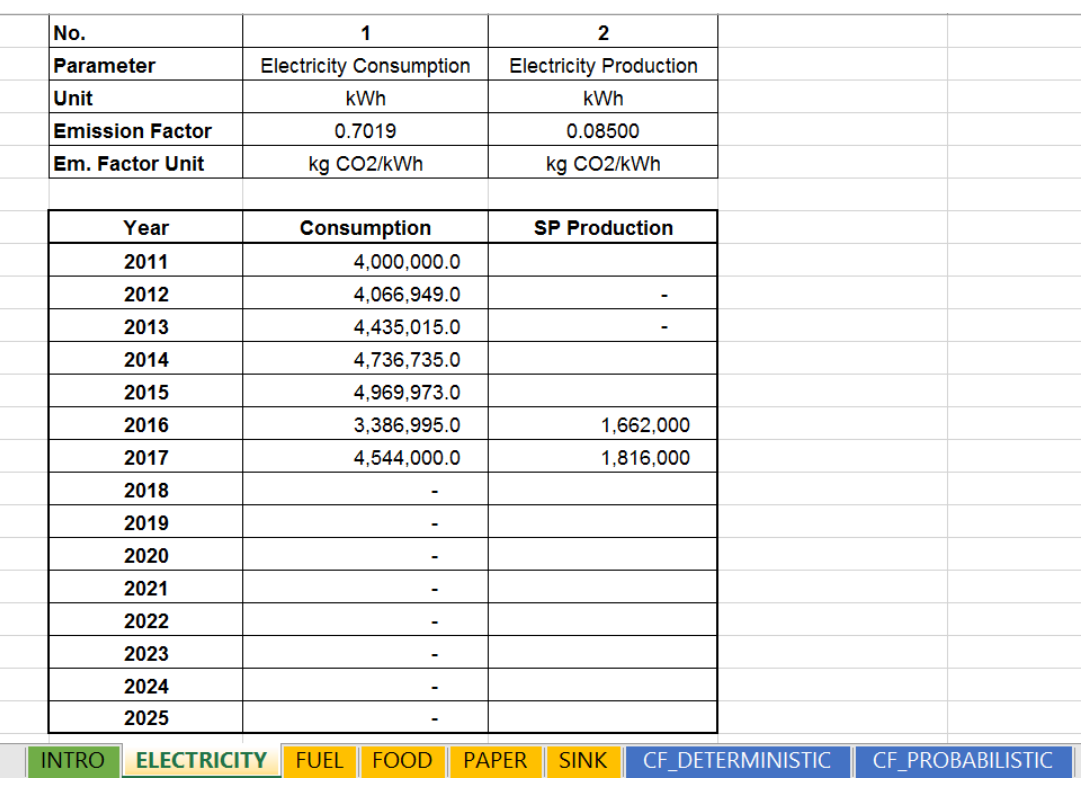

Figure 1. Organization of the spreadsheet tool 


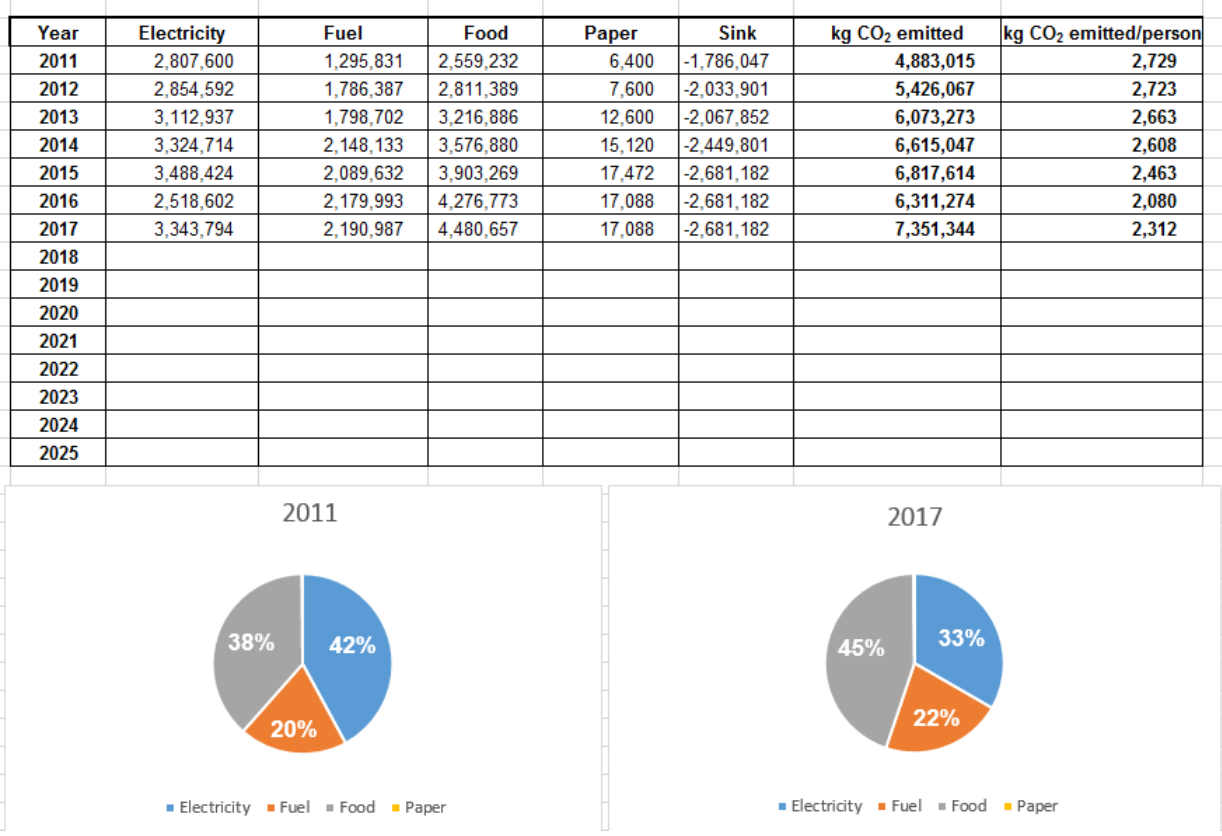

Figure 2. Spreadsheet for deterministic analysis of carbon footprint results

Probabilistic results worksheet (Figure 3) provides the user with the opportunity to enter estimates of certain consumption variables and some other estimates of input parameters such as number of students or employees. These estimates are given as minimum, maximum and most likely to define a triangular distribution of each variable. Using these estimations, a random-number-generator is used to generate 1,000 scenarios representing different combinations of all parameters and a Monte Carlo Simulation is performed. Clicking on the Run button runs the macro that calculates the frequency distribution of the total carbon emission and carbon emission per capita. Expectation curves are plotted automatically and P10, P50, P90 estimations are calculated through linear interpolation using a table look-up function.

Data collection is accomplished by working with administrative units in the campus and analyzing annual reports of the campus [19]. Following administrative units are contacted and following annual reports are analyzed to obtain the necessary data:

- Directorate of Administrative Affairs (number of cars, trees entering, paper consumption)

- Directorate of Constructional Services (electricity consumption/production, fuel consumption)

- Campus annual activity reports 2011-2016 [16] (number of students, employees)

Since it is a challenging task to determine the food consumption and fuel consumption due to daily commute, a survey was designed to have a rough estimation of those items. Based on daily eating habits, and daily commute to the campus from the residential location, average food consumption and average distance travelled by each student and employee were estimated. The emission amounts was obtained from the literature. Table 2 lists those factors.

It was desired to include number of trees as a carbon emission sink in the calculations, but this component may not provide realistic estimations for emission sink due to the following reasons: 1) There are relatively young trees in the campus, therefore their sink contribution would be limited, 2) There was not sufficient data regarding their weight/diameter estimations. Therefore, sink factors included in the calculations are written for a typical tree and they are not currently very realistic. In the future, it is desired to include more realistic estimations for this component of the calculation. Also, solid waste recycling was only performed for 1 year which made it difficult to consider it as a reliable data for multiple years. Therefore, solid waste recycling was not included in the calculations. 


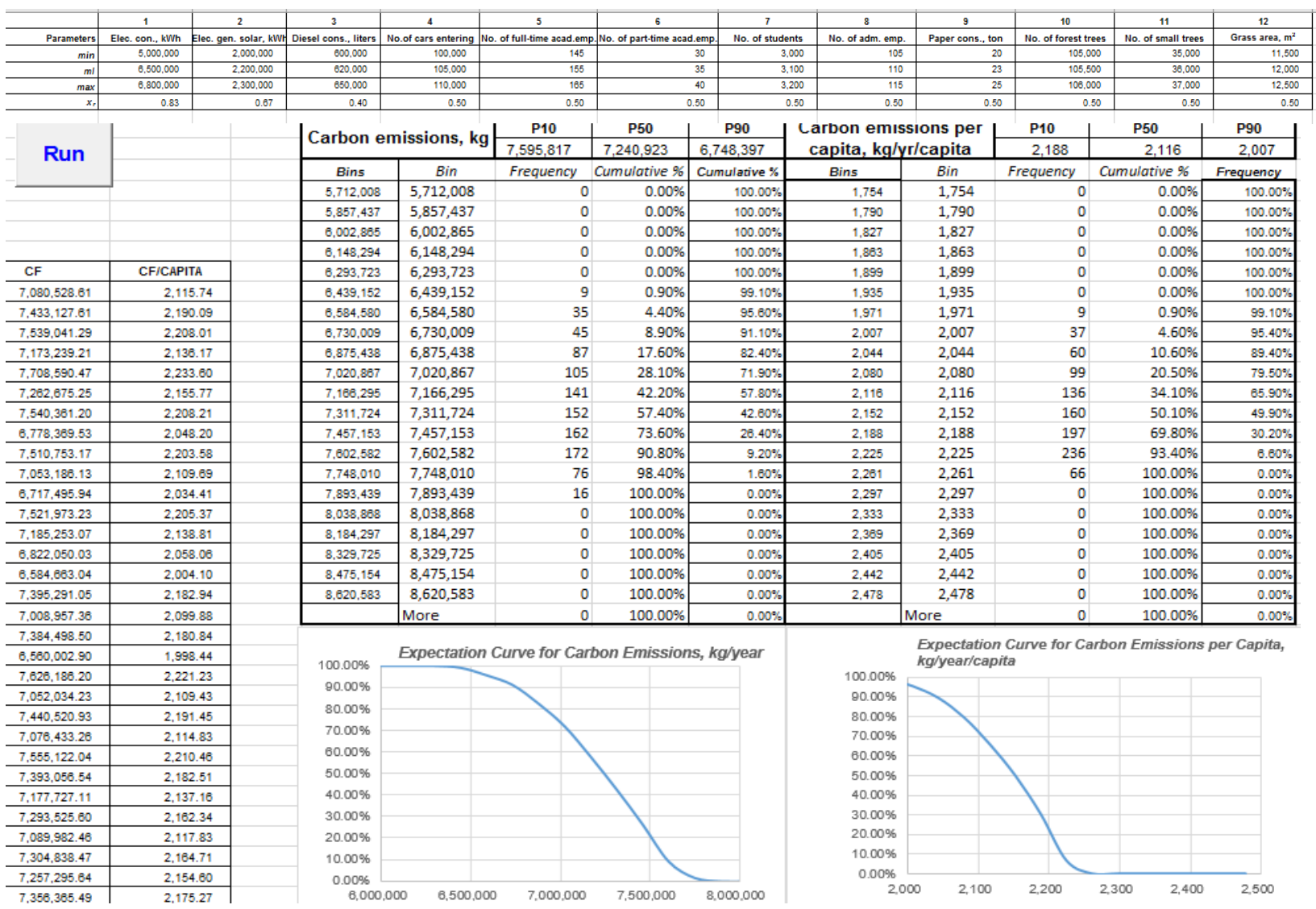

Figure 3. Spreadsheet for probabilistic analysis of carbon footprint results

\section{RESULTS AND DISCUSSION}

Each carbon-emission source was analyzed to understand their impact. When fuel consumption was analyzed it was observed that the number of cars entering to the campus per capita decreased by $44 \%$ since 2011 (Figure 4). Similarly, fuel consumption due to transportation per capita got reduced by $25 \%$. These are primarily attributed to three factors:

- Promotion of bicycle usage in the campus (Figure 5): Signs were placed on campus roads that indicate that roads are shared among pedestrians, bicycles and cars. A campus bike program was started that allows students/staff to rent bicycles for reasonable price.

- Shuttle buses for the commute of campus staff and students: The campus administration iniated a shuttle bus program that allows the campus staff and students to commute using these minivan type shuttles instead of their personal cars. The lack of public transportation in Northern Cyprus typically makes it a must to use personal vehicles for transportation. This initiative made it possible to commute to the campus location more efficiently.

- Increase in the public transportation frequencies and options for staff and students: Existing public transportation was very limited. The campus administration worked with the municipality to increase the frequency and options of public transportation between the campus and nearby villages and towns where most of the students and staff reside. 
Table 2. CO2 emission factors collected from the literature

\begin{tabular}{|l|l|l|l|l|}
\hline Emission Source & Unit & Emission Factor & Em. Factor Unit & Literature Source \\
\hline Electricity Consumption & $\mathrm{kWh}$ & 0.7019 & $\mathrm{~kg} \mathrm{CO}_{2} / \mathrm{kWh}$ & {$[20]$} \\
\hline $\begin{array}{l}\text { Electricity Production (solar } \\
\text { panel) }\end{array}$ & $\mathrm{kWh}$ & 0.085 & $\mathrm{~kg} \mathrm{CO} / \mathrm{kWh}$ & {$[20]$} \\
\hline Diesel cons. of generators & $\mathrm{kiters}$ & 2.93 & $\mathrm{~kg} \mathrm{CO}_{2} / \mathrm{liter}$ & {$[21]$} \\
\hline Commute (Personal Car) & $\mathrm{km} /$ year & 0.1868 & $\mathrm{~kg} \mathrm{CO}_{2} / \mathrm{km}$ & {$[21]$} \\
\hline Commute (Large Van) & $\mathrm{km} /$ year & 0.0208 & $\mathrm{~kg} \mathrm{CO}_{2} / \mathrm{km}$ & {$[21]$} \\
\hline Commute (Diesel Bus) & $\mathrm{km} /$ year & 0.034487 & $\mathrm{~kg} \mathrm{CO}_{2} / \mathrm{km}$ & {$[21]$} \\
\hline No. of cars entering & $\mathrm{car} /$ year & 0.5604 & $\mathrm{~kg} \mathrm{CO}_{2} / \mathrm{car}$ & {$[21]$} \\
\hline No. of flying staff & Person/year & 1501.1 & $\mathrm{~kg} \mathrm{CO}_{2} / \mathrm{person}$ & {$[21,22]$} \\
\hline Paper consumption & $\mathrm{tons} /$ year & 800 & $\mathrm{~kg} \mathrm{CO}_{2} / \mathrm{ton}$ & {$[23]$} \\
\hline Beef & $\mathrm{kg} /$ year & 27 & $\mathrm{~kg} \mathrm{CO}_{2} / \mathrm{kg}$ & {$[24]$} \\
\hline Poultry & $\mathrm{kg} /$ year & 6.9 & $\mathrm{~kg} \mathrm{CO}_{2} / \mathrm{kg}$ & {$[24]$} \\
\hline Fish & $\mathrm{kg} /$ year & 6.1 & $\mathrm{~kg} \mathrm{CO}_{2} / \mathrm{kg}$ & {$[24]$} \\
\hline Bottled water & $\mathrm{kg} /$ year & 0.166 & $\mathrm{~kg} \mathrm{CO}_{2} / \mathrm{kg}$ & {$[25]$} \\
\hline Vegetables & $\mathrm{kg} /$ year & 2 & $\mathrm{~kg} \mathrm{CO}_{2} / \mathrm{kg}$ & {$[24]$} \\
\hline Rice & $\mathrm{kg} /$ year & 2.7 & $\mathrm{~kg} \mathrm{CO}_{2} / \mathrm{kg}$ & {$[24]$} \\
\hline Bread & $\mathrm{kg} /$ year & 1.4 & $\mathrm{~kg} \mathrm{CO}_{2} / \mathrm{kg}$ & {$[26]$} \\
\hline Milk & $\mathrm{kg} /$ year & 1.9 & $\mathrm{~kg} \mathrm{CO}_{2} / \mathrm{kg}$ & {$[25]$} \\
\hline Cheese & $\mathrm{kg} /$ year & 13.5 & $\mathrm{~kg} \mathrm{CO}_{2} / \mathrm{kg}$ & {$[25]$} \\
\hline
\end{tabular}

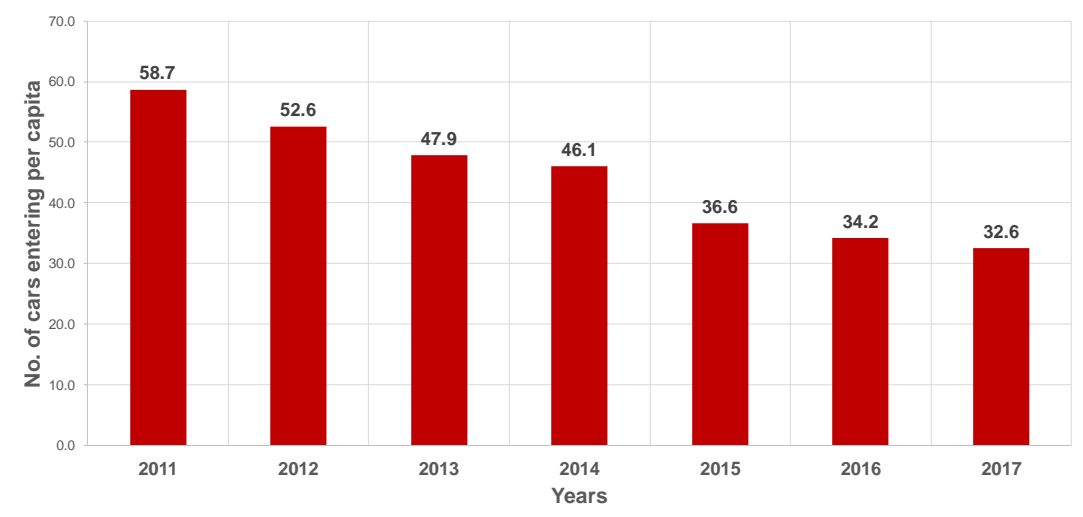

Figure 4. Number of cars entering to the campus per capita between 2011-2017

As a new campus at a relatively isolated location, METU NCC have had limited number of full-time faculty members, and education have been supported by part-time faculty members who travel every week during the semester. Carbon emissions due to transportation of these faculty members (flying and transportation to/from the airport) have been also taken into account in these calculations. However, their share resulted to be the lowest one among the three categories considered. It was observed that, among all sources of fuel consumption, diesel consumption has significantly higher share with $80.5 \%$ when compared with other two factors (Figure 6). 


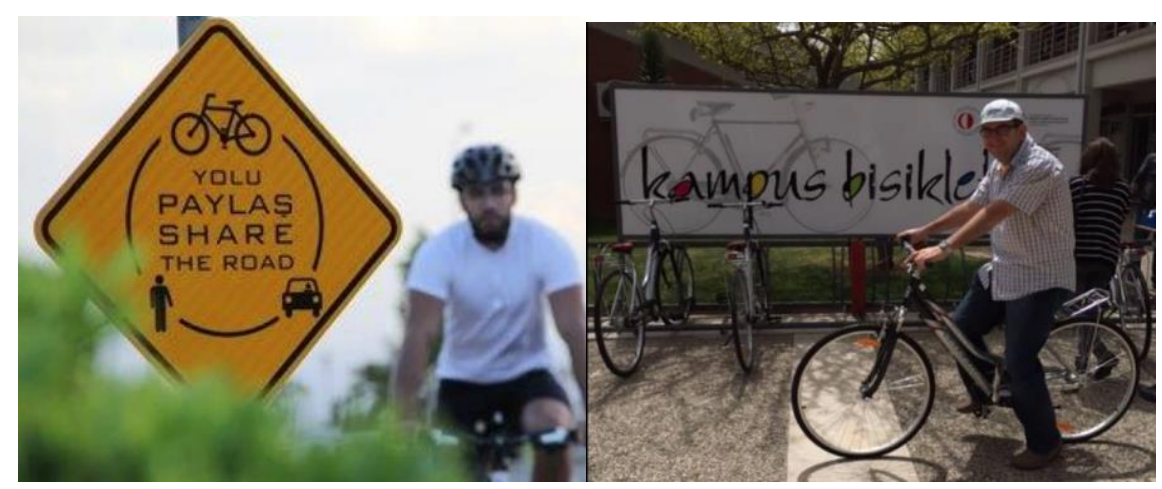

Figure 5. Road sharing and campus bike initiatives by METU NCC Green Campus Initiative

When we consider electricity consumption, an improvement observed due to the $1 \mathrm{MW}$ photovoltaic solar panel farm that has been in operation since April 2016. Solar panels have been producing, on average, $30 \%$ of the campus' electricity needs since that time. When we analyze the share of electricity consumption in terms of the contribution to the carbon emission sources, a reduction in the amount of $9 \%$ is observed (Figure 7). This can be probably attributed to the solar panels that were installed. Number of students who are studying in the campus has increased by \%92 (from approximately 1500 to 2900) within this 6-year time frame. Number of full-time employees increased from 199 to 255 (28\%). Since the total population of campus residents increased significantly (84\%), we would expect that the total amount of carbon emissions would also increase. Estimated carbon emissions indicate that annual carbon emission is $52 \%$ higher in 2017 than 2011, which is less than the increase in the population. When we analyze the carbon emissions per capita, which is a better indication of the sustainability-related improvements in the campus, we see a $15 \%$ decrease (Figure 8). This result indicate that the initiatives that has started and promoted within the campus contributed to the improvements in the carbon emissions. This actually is a very good improvement considering the strategic goal of reducing the carbon emissions more than 10\% [18].

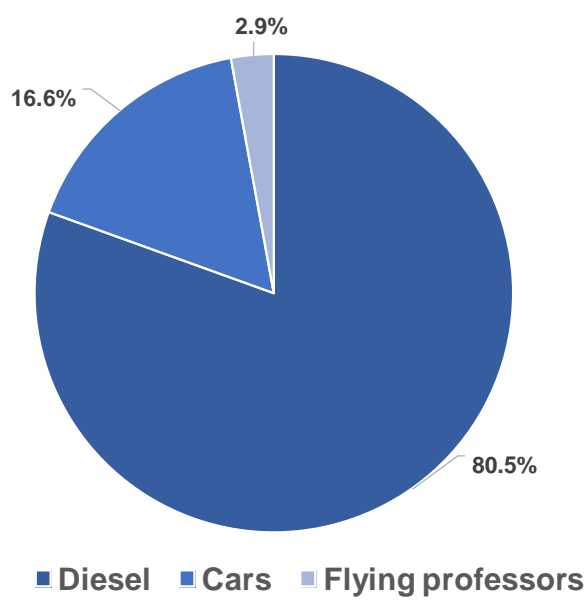

Figure 6. Contribution of different sources to fuel consumption in 2017 

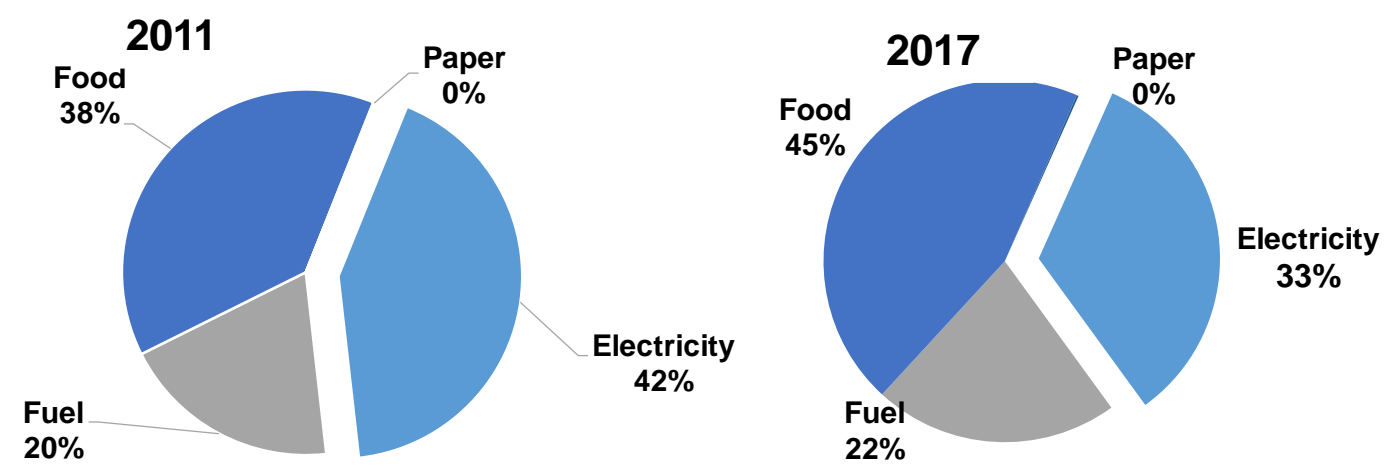

Figure 7. Contribution of different sources to carbon emissions in 2011 and 2017

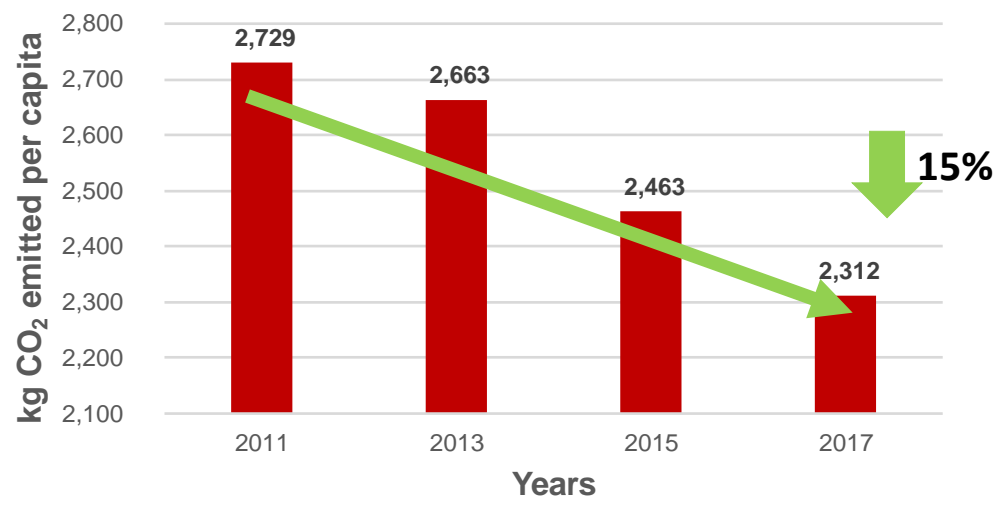

Figure 8. The change in carbon emissions per capita between 2011 and 2017

In studies that include forecasting of the future conditions, uncertainties in input parameters always exist due to unexpected events that may happen in the future. To be more realistic about the future, probabilistic estimation that incorporated uncertainty ranges is more reasonable. In this way, instead of a deterministic forecast, the results are shared with corresponding probabilities. One of the objectives of the spreadsheet is also to be able to forecast the emissions in the future. For a more realistic assessment, the spreadsheet is designed in a way that it allows Monte Carlo simulation technique. This technique requires to define the input parameters together with their statistical distributions. A large number of simulations are performed, which are randomly generated considering the defined distribution. The resulting calculation is a probabilistic distribution of values in a way that a range of values are output instead of a single estimate. This spreadsheet is shown in Figure 9. A sample forecast is performed by inputting the ranges of parameters. $\mathrm{CO}_{2}$ emitted per capita for this year is forecasted to be between 2,184 and 2,238 $\mathrm{kg}$. The expectation curve indicates the carbon emission values and corresponding probabilities of observing that amount. 

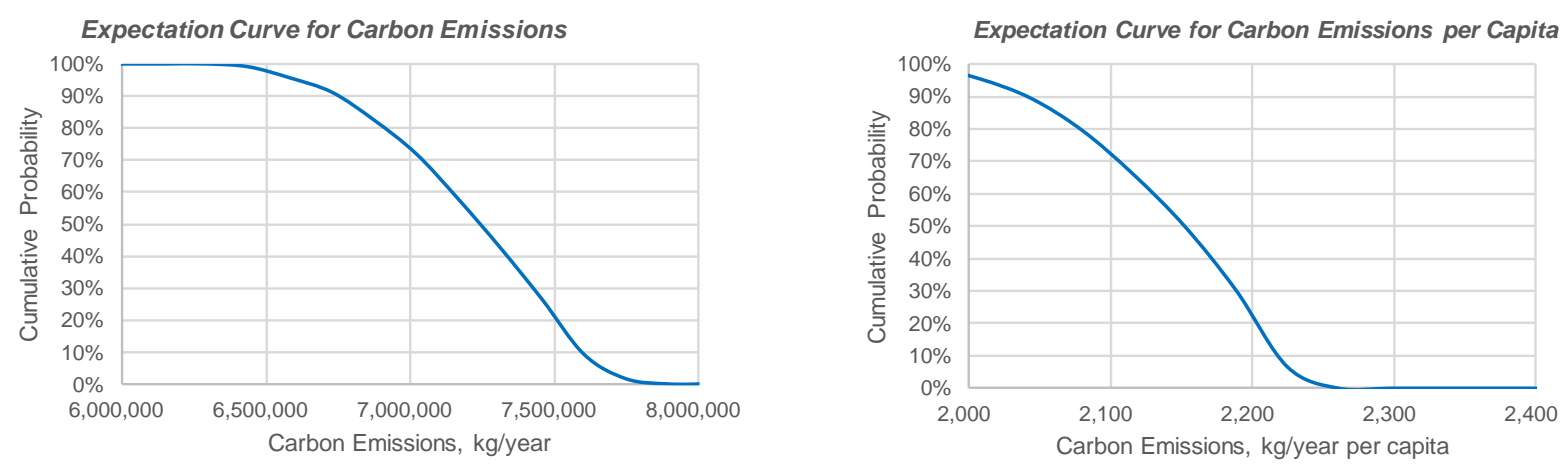

Figure 9. Sample probabilistic estimation of carbon footprint

\section{CONCLUSIONS}

The key conclusions of this study are as follows:

1. A spreadsheet tool to estimate carbon footprint of METU Northern Cyprus Campus was developed, which allows to estimate the carbon emissions from pre-determined sources using both deterministic and probabilistic approaches,

2. Carbon footprint estimations are calculated using available data collected from annual reports, surveys and administrative units as well as carbon emission factors collected from the literature,

3. Solar power plant that was built in the campus decreased the carbon emissions of the campus' electricity consumption,

4. Importance of and the need for data collection were demonstrated to assess carbon emissions continuously,

5. The increased use of bicycles, shuttle busses for the campus staff helped to reduce the fuel consumption due to daily transportation. This highlights the importance of this kind of initiatives in university campuses.

6. With the help of the Green Campus Initiative, carbon emissions were reduced by more than $10 \%$ during the time period that was analyzed in this study. This demonstrates the importance of such kind of initiatives to reduce the environmental impact of a university campus.

\section{CONFLICTS OF INTEREST}

No conflict of interest was declared by the author.

\section{ACKNOWLEDGEMENTS}

This study was funded by a research grant, Middle East Technical University - Northern Cyprus Campus (METU NCC) Campus Research Fund Project No. FEN-16-D-2 and this support is acknowledged. Author would like to thank METU NCC General Secreteriat, Departments of Administrative Affairs and Construction Services, METU NCC Green Campus Initiative Coordination Unit and Ege Gulen (Sustainable Environment and Energy Graduate Program Student) for their help in collecting and organizing the data used in this study. 


\section{REFERENCES}

[1] Solomon, S., Platter, G. K., Knutti, R., Friedlingstein, P., "Irreversible climate change due to carbon dioxide emissions", Proceeding of the National Academy of Sciences, 106: 1704-1709, (2009).

[2] Turanli, A. M, "Estimation of carbon footprint: a case study for Middle East Technical University", M.Sc. Thesis, Middle East Technical University, Ankara, Turkey, (2015).

[3] Wackernagel, M., Onisto, L., Bello, P., Linares, A. C., López Falfán, I. S., García, J. M., Suárez Guerrero, A. I., Suárez Guerrero, M. G., "National natural capital accounting with the ecological footprint concept", Ecological Economics, 29, 375-390, (1999).

[4] Wackernagel, M., Schulz, B., Deumling, D. Linares, A. C., Jenkins, M., Kapos, V., Monfreda, C., Loh, J., Myers, N., Norgaard, R. and Randers, J., "Tracking the ecological overshoot of the human economy”, Proceeding of the National Academy of Sciences, 99(14): 9266-9271, (2002).

[5] Wiedmann, T., Minx, J., Barrett, J., Wackernagelc, M., “Allocating ecological footprints to final consumption categories with input-output analysis", Ecological Economics, 56(1): 28-48, (2006)

[6] Wright, L., Kemp, S., Williams, I., "Carbon footprinting: towards a universally accepted definition", Carbon Management, 2(1): 61-72, (2011).

[7] Galli, A., Wiedmann, T., Ercin, E., Knoblauch, D., Ewing, B., Giljum, S., "Integrating ecological, carbon and water footprint into a 'footprint family' of indicators: definition and role in tracking human pressure on the planet”, Ecological Indicators, 16: 100-112, (2012).

[8] Univ. of Mount Union, "University of Mount Union sustainability plan - incorporating a climate action plan", (2010).

[9] Colby College, "Green Colby Initiative", Colby College, Waterville, Maine, USA. http://www.colby.edu/green/ Access date: 20.04.2020.

[10] Univ. of New Hampshire “Campus Carbon Calculator v. 6.5 User's Guide”, (2010).

[11] Taylor, B. “Colgate University’s 2008-09 Comprehensive Carbon Inventory”, (2010).

[12] IPCC, "Intergovernmental Panel on Climate Change, Third Assessment Report", Switzerland, (2001).

[13] IPCC, "Intergovernmental Panel on Climate Change (IPCC) National Greenhouse Gas Inventories - Guidelines", Japan, (2006).

[14] IPCC, "Intergovernmental Panel on Climate Change, Fourth Assessment Report" Switzerland, (2007).

[15] METU NCC, Official Web Site, General Information https://ncc.metu.edu.tr/general-information Access date: 13.02 .2020 .

[16] KKTC YÖDAK, Official Web Site, Universities https://yodak.gov.ct.tr/\%C3\%9Cniversitelerimiz Access date: 13.02.2020. 
[17] Times Higher Education - World University Rankings Wb Site, Top universities with the best student-to-staff ratio 2020, https://www.timeshighereducation.com/student/best-universities/topuniversities-best-student-staff-ratio Access date: 13.02.2020.

[18] METU NCC, "Green Campus Initiative: Green Campus Strategy Document", Middle East Technical University Northern Cyprus Campus, Kalkanli-Guzelyurt, TRNC, (2013).

[19] METU NCC, “Annual Reports 2011-2016”, Middle East Technical University Northern Cyprus Campus, Kalkanli-Guzelyurt, TRNC, (2011).

[20] WNA, "Comparison of greenhouse gas emissions of various electricity generation sources" ,World Nuclear Association Report, (2011).

[21] EPA. "Emission factors for greenhouse gas inventories" U.S. Environmental Protection Agency Report, (2014).

[22] Boeing, "Boeing 737 NG Performance Summary”, Boeing Report, Chicago, Illinois, USA, (2007).

[23] ATS, "Paper \& the environment, myths and realities", ATS Consulting Report (2007).

[24] http://www.greeneatz.com/foods-carbon-footprint.html Access date: 20.04.2020

[25] https://tappwater.co/us/carbon-footprint-bottled-water/ Access date: 20.04.2020

[26] Espinoza-Orias, N, Stichnothe, H., Azapagic, A. "The carbon footprint of bread”. International Journal of Life Cycle Assessment, 16: 351-365, (2011). 